DOI: 10.12957/demetra.2016.22485

\title{
Considerações conceituais acerca da subjetividade masculina para o campo da Alimentação e Nutrição
}

\section{Conceptual considerations about male subjectivity to the realm of feeding and nutrition}

\author{
Roberto Carvalho Alves Filho' \\ Francisco Romão Ferreira ${ }^{2}$ \\ Cristiane Marques Seixas ${ }^{3}$ \\ Fabiana Bom Kraemer ${ }^{3}$ \\ 1 Universidade do Estado do Rio de Janeiro, \\ Instituto de Nutrição, Programa de Pós- \\ graduação em Alimentação, Nutrição e Saúde. \\ Rio de Janeiro-RJ, Brasil. \\ ${ }^{2}$ Universidade do Estado do Rio de Janeiro, \\ Instituto de Nutrição, Programa de Pós- \\ graduação em Alimentação, Nutrição e Saúde, \\ Núcleo de Estudos sobre Cultura e Alimentação. \\ Rio de Janeiro-RJ, Brasil. \\ ${ }^{3}$ Universidade do Estado do Rio de Janeiro, \\ Instituto de Nutrição, Núcleo de Estudos sobre \\ Cultura e Alimentação. Rio de Janeiro-RJ, Brasil. \\ Correspondência / Correspondence \\ Roberto Carvalho Alves Filho \\ E-mail: rcalvesł@hotmail.com
}

\section{Resumo}

O presente ensaio apresenta algumas reflexões iniciais construídas no decorrer da produção da dissertação de mestrado intitulada $A$ Saúde no corpo do homem: a construção da subjetividade acerca do corpo masculino na revista Men's Health. Apresentamos alguns conceitos e referências teóricas utilizadas na dissertação e consideramos este ensaio como uma primeira articulação entre as discussões sobre gênero, saúde, alimentação e consumo. Pretendemos apresentar um mosaico de questões a partir da perspectiva de Howard Becker, para quem a imagem do mosaico é útil, pois nele cada peça acrescentada contribui um pouco para a compreensão do todo. Deste modo, os diferentes fragmentos teóricos aqui reunidos compõem o mosaico e contribuem de modo diferente para nossa compreensão de como a comida, as diferentes masculinidades, os cuidados com a saúde e os discursos da ciência, da mídia e do mercado se articulam no que se intitula "saúde do homem", produzindo novas subjetividades afeitas ao consumo de modelos ideais de corpo e saúde.

Palavras-chave: Masculinidade. Saúde. Ciências Sociais. Nutrição. Alimentação. Saúde do Homem.

\section{Abstract}

This essay presents some reflections produced in the course of writing the master thesis entitled "Health in the human body: the construction of subjectivity about the male body in Men's Health magazine". We present some concepts and theoretical references used in the thesis and we consider this essay as the 
first articulation between the discussions about gender, health, feeding and consumption. We intend to present a mosaic of issues based on Howard Becker's perspective (1994), to whom the mosaic image is useful because each piece added contributes to some extent to the knowledge of the whole picture. Thus, the different theoretical fragments joined here arrange the mosaic and contribute differently to our knowledge about how food, different masculinities, health care and the discourses of science, the media and the market articulate themselves in the meaning of "human health", thus bringing forth new subjectivities attached to the consumption of ideal models of body and health.

Key words: Masculinity. Health. Social Sciences. Nutrition. Food. Men's health.

\section{Introdução}

Quando se fala da saúde do homem, lembramos imediatamente dos estereótipos que tentam padronizar a masculinidade como uma única forma de ser homem a partir de um modelo de corpo ideal e de uma forma específica de pensar e se comportar. Tais estereótipos produzem um discurso simplista e superficial que nos afasta da possibilidade de pensar seriamente sobre a relação do homem com seu próprio corpo, com os cuidados com a saúde e alimentação, assim como com as diferentes masculinidades presentes na vida social. No momento atual, a saúde do homem tem se tornado objeto de interesse para a sociedade. Tanto o senso comum, quanto a ciência, a mídia e a publicidade investem de forma intensa na masculinidade, tentando construir processos de subjetivação que atendam aos interesses do mercado e sua lógica de consumo. Criam-se, assim, estratégias para cooptar o homem pela moda, pelo culto ao corpo perfeito e pelos cuidados com a estética que, por seu turno, levam a novos padrões de comportamento que utilizam a alimentação como um dos principais dispositivos de subjetivação para a obtenção da sonhada saúde perfeita.

A construção da masculinidade em sua relação com a alimentação incorpora inúmeras questões. Temas como a distinção social pelo consumo a partir da "gourmetização" da comida, a profusão de programas e séries de televisão com o protagonismo do homem na cozinha, a medicalização do alimento para se obter resultados imediatos, a funcionalidade dos alimentos para atuações específicas no organismo, a construção da imagem corporal como uma máquina infalível a serviço da performance e a preocupação crescente com a estética, são alguns dos novos sentidos e significados atribuídos ao alimento. As novas relações sociais presentes no ato de comer e os modos próprios como os homens lidam com essas questões são temas de interesse geral e bastante relevantes para o campo científico da Alimentação e Nutrição. 
Apresentamos aqui algumas reflexões iniciais construídas no decorrer da produção da dissertação de mestrado intitulada $A$ saúde no corpo do homem: a construção da subjetividade acerca do corpo masculino na revista Men's Health. ${ }^{1}$ De modo geral, a pesquisa objetivou analisar os códigos de construção do corpo e da identidade masculina no campo da Alimentação e da Nutrição a partir da revista Men's Health, ${ }^{1}$ apresentando de forma crítica o modo como os homens são abordados nessa publicação. Buscou-se perceber a construção da imagem corporal e a transformação da comida em objeto de consumo, distinção social e uma funcionalidade no organismo que se apresenta de forma pragmática e imediatista, demonstrando o olhar mecanicista, reducionista e tecnicista do corpo masculino presente na revista, assim como o reforço dos estereótipos do senso comum que impedem uma reflexão crítica. A preocupação com a performance no mundo social, na vida sexual e no ambiente competitivo do trabalho transformam a comida no "combustível" ideal para a máquina, e o corpo é reduzido a um mecanismo que se pode alterar, programar e controlar, desconsiderando neste processo qualquer vestígio de subjetividade ou interioridade. O corpo é visto como o instrumento que se controla para a obtenção do que supostamente se deseja.

Apresentamos alguns conceitos e referências teóricas utilizadas na dissertação e consideramos este ensaio como uma primeira articulação entre as discussões sobre gênero, saúde, alimentação e consumo. Não pretendemos, portanto, discutir exaustivamente e aprofundar questões específicas de um campo ou de outro; pelo contrário, nosso interesse é apresentar um mosaico teórico, composto por notas preliminares e aproximações conceituais que permitem fazer algumas reflexões sobre um tema pouco estudado no campo da Alimentação e Nutrição.

O campo da Nutrição, tradicionalmente, reproduz um modo de pensamento mais afeito ao campo biomédico, que é hegemônico no campo da saúde, e poucos trabalhos discutem a construção da identidade e subjetividade masculinas, utilizando as referências conceituais das Ciências Sociais. Trata-se, portanto, de um campo de estudos em construção, e este trabalho talvez possa constituir uma primeira articulação acerca da construção da subjetividade masculina em sua relação com a comida.

Utilizamos o termo "mosaico" a partir da perspectiva de Howard Becker, ${ }^{2}$ para quem "a imagem do mosaico é útil para pensarmos sobre este tipo de empreendimento científico. Cada peça acrescentada num mosaico contribui um pouco para nossa compreensão do quadro como um todo". Assim, os diferentes fragmentos que compõem o mosaico contribuem de modo diferente para nossa compreensão e nenhuma das peças está solta, sem sentido; todas estão em relação umas com as outras.

Notamos que o quadro conceitual que fundamenta os discursos presentes na revista Men's Health ${ }^{1}$ tem referência o discurso científico. Nessas publicações, há uma mistura de discurso publicitário, discurso científico, marketing de empresas, venda de produtos, bens e serviços, discurso médico especializado e senso comum - enfim, uma miríade de conceitos e discursos que se articulam 
com o objetivo de vender algo para o público. Pensar a comida, as diferentes masculinidades, os cuidados com a saúde e os discursos da ciência, da mídia e do mercado significa juntar diferentes peças desse mosaico que se intitula "saúde do homem", com a originalidade de pensar isto a partir do campo da Alimentação e Nutrição.

As normas de gênero e o corpo do novo homem

O universo masculino é uma área de interesse relevante para o campo científico que inclui as discussões sobre gênero. Diversos conceitos advindos de outros campos contribuem para dar corpo a uma discussão que é relativamente recente, mas também sofrem críticas e reformulações. O conceito de masculinidade hegemônica, por exemplo, foi inicialmente proposto por Kessler et al., ${ }^{3}$ em discussão conceitual a respeito da construção das masculinidades e do corpo dos homens, sistematizada no artigo "Towards a new sociology of masculinity," onde se elaborou uma crítica ao papel sexual masculino, propondo um modelo de "masculinidades" em múltiplas relações de poder.

Connell \& Messerschmidt ${ }^{5}$ retomam o percurso deste conceito que incorpora tanto estudos a respeito dos homens como aspectos do senso comum sobre homens e meninos, posiçóes feministas sobre o patriarcado e modelos sociais de gênero, indicando a necessidade de sua reformulação em termos contemporâneos. Para os autores, a masculinidade hegemônica foi entendida como um padrão de práticas que possibilitou que a dominação dos homens sobre as mulheres continuasse e, apesar de não ser adotada por todos os homens, constitui uma normatividade relacionada ao gênero. A masculinidade hegemônica "incorpora a forma mais honrada de ser um homem, ela exige que todos os outros homens se posicionem em relação a ela e legitima ideologicamente a subordinação global das mulheres aos homens". ${ }^{5}$

Segundo Jansen \& Sabo, ${ }^{6}$ o conceito também foi utilizado em pesquisas sobre as representações do homem na mídia, ajudando a dar sentido à diversidade e à seletividade das imagens na mídia de massa, ocasionando um mapeamento das relações entre diferentes representações das masculinidades. É nesse quadro teórico-conceitual que se observa o surgimento na mídia brasileira da ideia de um "novo homem" como modelo a ser seguido. Diferentemente do "antigo homem" que se alinhava com um modelo hegemônico de masculinidade baseado na família tradicional moderna, esse "novo homem" configura-se como um "avanço" ao assumir mudanças em certos valores e crenças típicos da masculinidade tradicional, passando a exigir dos homens mais cuidado com o corpo e a aparência e afastando-se, ao mesmo tempo, da homossexualidade. ${ }^{7}$

Seguindo essa tendência dos meios de comunicação de massa, em maio de 2006, a Editora Abril lançou no Brasil a revista Men's Health, ${ }^{1}$ numa tentativa de modificar o mercado editorial criando uma "novo" nicho para o público masculino e mantendo os assuntos tradicionais das outras revistas masculinas, porém com outra forma de apresentação. Numa clara tentativa de 
ampliar o conceito de homem, a revista inovou também ao trazer assuntos até então reconhecidos como mais próprios ao universo das mulheres e dos homossexuais, como sexualidade, cuidado com a saúde e a estética, estilo, moda, comportamento social etc. ${ }^{7}$. A alimentação também ganhou importância considerável, uma vez que contribui para a construção de corpos belos e saudáveis. Tal empreendimento é índice de uma tentativa de abrir um novo mercado de consumo de bens, ideias, serviços e produtos junto ao universo masculino, que até então era bastante conservador em seus hábitos cotidianos, permitindo poucas variações e nuances nos produtos oferecidos.

O investimento desse mercado aponta agora para um novo universo de consumidores que anteriormente não consumiam tais produtos, pois agora há um crescimento acima do padrão econômico médio, do mercado de produtos e serviços ligados à estética (como cremes, xampus, tratamentos, perfumes, loções, salões de beleza mais sofisticados, clínicas de estética e serviços de depilação). A alimentação também participa deste filão de mercado ao oferecer shakes, suplementos, dietas, receitas e comidas que servem para melhorar a aparência e a performance. São produtos e serviços que cada vez mais se especializam para entender este novo homem e oferecer os produtos que o transformarão no modelo metrossexual ${ }^{a}$ que se firma como o padrão estético da masculinidade contemporânea. Ser um macho peludo é coisa do passado; o novo homem é depilado, faz as unhas, passa cremes na face, usa gel no cabelo e consome alimentos saudáveis e funcionais. Tudo acompanhado por profissionais especializados.

A revista se torna um veículo privilegiado no surgimento e manutenção da nova masculinidade, pois pretende instituir um novo jeito de ser homem. Observa-se uma tentativa de deixar o "novo homem" mais próximo do universo da indústria cosmética, da medicina estética e da moda, mas sem comprometer o coeficiente de macheza do futuro consumidor. Pelo contrário, esse novo homem supostamente sai na frente na hora da conquista sexual e/ou profissional. O novo macho cuida da pele, da dieta e da imagem, e sua identidade é construída a partir dos produtos disponíveis no mercado.

\section{O corpo como um conceito}

Com o intuito de abrir novas reflexões para o campo da Alimentação e Nutrição, destacamos os termos "corpo", "alimentação", "masculinidade" e "saúde", que, nesse contexto, apresentam-se como relevantes uma vez que, ao se articularem, contribuem de modo significativo para a empreitada rumo a uma nova masculinidade. Tais termos não são apenas palavras, mas conceitos que traduzem os diferentes valores e posições ideológicas presentes nos estudos acerca das masculinidades.

a O termo "metrossexual" foi usado pelo jornalista Mark Simpson em 1994 em uma coluna no jornal inglês The Independent. 
Para Deleuze, ${ }^{8}$ não há conceito simples, pois é sempre composto por múltiplos interesses, percepções. Não há conceito isolado, neutro, puro ou inocente. O conceito está sempre em relação com outros conceitos e discursos. Neste sentido, todo conceito é duplo, triplo, múltiplo, composto por partes distintas e, ao se expor, revela suas articulações, seus componentes, suas superposições. Todo conceito, então, remete a um problema que lhe dá sentido, um discurso que o orienta, estabelecendo relações de convergência ou divergência com outros discursos afins ou antagônicos, buscando estabelecer e impor modos de compreensão da realidade, transformando percepções e formulações teóricas em linguagem que será aceita e assimilada pelo senso comum.

Partindo dessa consideração, o corpo não é apenas a matéria, carne e ossos, um mero organismo biológico com seus órgãos e sistemas; pelo contrário, o corpo é construído pela cultura e pelos discursos presentes na sociedade, em uma articulação sócio-histórica ininterrupta e transitória. O corpo, portanto, pode ser pensado como um conceito, como um constructo do pensamento científico do campo biomédico ${ }^{9}$ que nele coloca seus interesses, atualiza seus discursos, seus pontos de vista e sua epistemologia. Desta forma, pensar o corpo é pensar seus conceitos, seus modos de apresentação na cena científica e nos discursos que o constituem nas ciências da saúde. Ao mesmo tempo, o corpo é natureza, um organismo biológico, e também é cultura, um conjunto de significados criados segundo interesses específicos dos diferentes atores sociais que produzem discursos sobre o corpo.

O discurso sobre o corpo que aparece nas revistas masculinas traduz conceitos arraigados no senso comum, como também apresenta claramente o interesse de uma racionalidade médica instrumental e tecnicista, além do discurso oportunista e tendencioso da publicidade e do mercado. Tais discursos apresentam concepções, representações e conceitos que ajudam a construir determinada fundamentação acerca do corpo, mas reduzindo-o à dimensão biológica e sua inserção na sociedade através do consumo e do culto ao "corpo perfeito".

O conceito de corpo utilizado nesta estratégia é reducionista, tecnicista e mecanicista. Reduz o corpo aos elementos biomédicos ou biomecânicos, desvaloriza ou ignora os aspectos subjetivos na construção da identidade masculina, coloca o feminino como algo secundário, uma espécie de troféu a ser conquistado após a transformação, não considera as diferentes masculinidades e constrói um ideal de corpo a partir das estratégias do mercado, da medicina estética e da indústria de cosméticos. O novo homem é apenas forma sem conteúdo.

\section{O discurso sobre a saúde na revista Men's Health}

Pensar o corpo, então, significa pensar os diferentes conceitos e discursos que o constituem. O conceito é a base do discurso, é o seu "núcleo duro", pois ele formula um mundo possível, uma realidade própria construída, um "discurso legítimo", cientificamente correto. Os conceitos sobre o 
corpo presentes na revista Men's Health ${ }^{1}$ se articulam, se relacionam e se conectam a outros conceitos do campo biomédico, da mídia, da publicidade, do universo da indústria cultural, reproduzindo os valores do narcisismo e do consumismo característicos da atualidade. Neste sentido, conciliamos a relação entre a construção da identidade masculina pela via do corpo idealizado, tendo em vista como o alimento é capturado numa lógica de consumo e reiterado nos discursos da revista estudada. A discussão sobre o gênero se presta e revelar como discursos dominantes operam na formatação de uma subjetividade hegemônica, lançando mão de recursos que outrora se encontravam fora do universo masculino.

O paradigma científico dominante no mundo moderno tem sua origem na teoria heliocêntrica do movimento dos planetas de Copérnico, nas leis de Kepler sobre as órbitas dos planetas, nas leis de Galileu sobre a queda dos corpos, na grande síntese operada por Newton. No século XVII, o desenvolvimento da mecânica influenciou o pensamento do filósofo René Descartes, que afirma o corpo humano como máquina, bastando saber o defeito para ser consertado. Ele cria, assim, uma racionalidade científica que coloca o corpo como objeto, mero instrumento do conhecimento, à mercê de uma racionalidade científica que produz saberes, conceitos e verdades acerca do corpo que, por sua vez, vão se diluir e penetrar no conjunto da sociedade, diluindo-se no senso comum. Mas esse pensamento, apesar de hegemônico, não constitui unanimidade.

Segundo Boaventura Souza Santos, ${ }^{10}$ trata-se de um modelo totalitário que nega um caráter racional a todas as formas de conhecimento que não operem segundo sua lógica, que não se pautem por seus princípios epistemológicos e por suas regras metodológicas. Para o autor, esse modelo científico apresenta características marcantes, tais como: o conhecimento acontece pelo rigor na quantificação e os aspectos qualitativos são descartados; a complexidade é reduzida, devendo-se dividir para conhecer; e a criação de leis regulares que visam prever o futuro do fenômeno. O mundo, e por consequência o corpo, o humano, a alimentação e tudo que faz parte da vida, adquirem esta lógica do mundo-máquina de tal modo poderosa, que vai se transformar na grande hipótese universal da época moderna, o mecanicismo. ${ }^{10}$

Assim, essas diretrizes constituem o que hoje denominamos "ciência" e instituem a racionalidade biomédica na saúde. Segundo Camargo Jr., ${ }^{9}$ essa racionalidade é delimitada pelo caráter generalizante com validade universal em detrimento da singularidade; pelo caráter mecanicista, causalidades homogêneas que descrevem o mundo todo; e pelo caráter analítico, que produz um isolamento das partes, que depois juntas demonstram o funcionamento do todo. A lógica racionalista moderna apontada por Santos e Camargo Jr. apresenta-se com uma nitidez na ideologia do momento histórico em que vivemos, e comparece categoricamente na intenção do editorial da revista Men's Health, ${ }^{1}$ sobretudo na forma de compreender e praticar saúde.

Nesse sentido, após a Segunda Guerra Mundial, com a criação da Organização das Nações Unidas (ONU) e da Organização Mundial da Saúde (OMS), o conceito de saúde passou a ser 
definido como o estado completo de bem-estar físico, mental e social. Junto a ele, emergiu um modelo de saúde biopsicossocial em contraponto ao modelo biomédico. Enquanto o primeiro considera a pessoa como um todo, o segundo valoriza as partes do organismo, caracterizando-se por uma racionalidade reducionista e mecanicista, como aludimos anteriormente.

Acreditamos que a revista Men's Health ${ }^{1}$ reproduz esse modelo totalitário de ciência, que valoriza o corpo ao extremo, até o limite de apagar sua pluralidade. Reforça a ideologia mecanicista do corpo defeituoso e frágil que necessita ser consertado, subordinando-o à máquina, tornando-o uma mercadoria fetichizada. ${ }^{11}$ Ao conferir ao discurso científico dos especialistas a chancela da verdade, reitera um discurso de autoridade que banaliza a discussão de gênero e reforça os estereótipos de força, vigor, sucesso e competitividade da heteronormatividade.

\section{Corpo, fetiche do mercado}

Com o pensamento do sociólogo polonês Zygmunt Bauman, ${ }^{12}$ aprendemos que a sociedade contemporânea vem perdendo os aportes físicos e ideológicos rígidos de tempos atrás. Vivemos em uma sociedade fluida de medos e amores líquidos, onde as pessoas vão sendo transformadas em mercadorias descartáveis, no contexto de uma sociedade de consumo, onde a imagem (marca industrial/marca corporal) dá ao sujeito sua identidade.

Para Bauman, ${ }^{13}$ as pessoas são aliciadas, estimuladas ou forçadas a promover uma mercadoria atraente e desejável. Para tanto, fazem o máximo possível e usam os melhores recursos que têm à disposição para aumentar o valor de mercado do produto que estão vendendo. E os produtos que elas são encorajadas a colocar no mercado, promover e vender, são elas mesmas. São, ao mesmo tempo, os promotores das mercadorias e as mercadorias que promovem. São, simultaneamente, o produto e seus agentes de marketing, os bens e seus vendedores. O novo homem é reduzido a um novo produto, um novo lançamento no mercado; ele é o garoto propaganda de si mesmo.

Ainda segundo Bauman, ${ }^{13} \mathrm{o}$ destino final de toda mercadoria colocada à venda é ser consumida por compradores e na sociedade de consumidores, ninguém pode se tornar sujeito sem primeiro virar mercadoria. Ninguém pode manter segura sua subjetividade sem reanimar, ressuscitar e recarregar de maneira perpétua as capacidades esperadas e exigidas de uma mercadoria vendável. Há um "embaçamento", uma eliminação das fronteiras entre seres e coisas. ${ }^{13}$ Nesta perspectiva, a construção da identidade masculina na revista é um simulacro - uma representação - e o que se supõe ser a materialização da verdade interior é uma idealização dos traços materiais - objetificados e coisificados - das escolhas do consumidor. A satisfação, a promessa de felicidade, a valorização da performance e os resultados do "investimento" são imediatos, tudo "aqui e agora", rápido e fácil. O corpo ideal do "novo" homem é obtido de forma instantânea, a promessa de felicidade é 
perpétua e ele se transforma, ele próprio, em mercadoria de consumo. E ser uma mercadoria de consumo é o que o torna membro autêntico da nossa sociedade.

Tendo em vista a noção de simulacro, podemos considerar que poucos conceitos têm tanta relevância na modernidade quanto o de fetiche, sendo utilizado por vários cientistas e escritores. Foi pensado inicialmente por Charles de Brosses, escritor francês em 1756, o qual permitia estabelecer os limites entre nossas sociedades esclarecidas e as sociedades primitivas com crenças e superstições, pretensamente sujeitas a um sistema encantado de crenças supersticiosas. $\mathrm{O}$ autor dedicou um livro a determinar as coordenadas histórico-geográficas do pensamento primitivo por meio da identificação de uma forma de encantamento cuja ilustração perfeita seria o culto aos ditos deuses fetiches. Essa caracterização do pretenso pensamento primitivo por meio do fetichismo atravessou os séculos XVIII e XIX. ${ }^{14}$ Ora, não seriam vestígios desses "deuses fetiches" que vemos hoje serem construídos na mídia? Assim, a articulação entre o conceito de fetichismo freudiano e de fetichismo da mercadoria em Marx é importante para compor o mosaico teórico percorrido para pensar as relações de poder que estão em jogo nas construções de corpo, saúde, alimentação e masculinidade revista em questão.

Marx pensa a mercadoria como produto humano para a troca, com o objetivo econômico de valorizar o capital, transformando o valor concreto em um valor abstrato. Os objetos ganham valores ideologicamente produzidos em um movimento de idealização (fetiche), criando desejos a serem consumidos. Portanto, nessa articulação, propomos que o corpo se torna também um objeto de fetiche.

Na sociedade capitalista, os objetos materiais possuem certas características que lhe são conferidas pelas relações sociais dominantes, mas que aparecem como se lhes pertencessem naturalmente. A analogia é feita com a religião, na qual as pessoas conferem a alguma entidade um poder imaginário. Só que não são propriedades naturais, são sociais - constituem forças reais, não controladas pelos seres humanos e que, na verdade, exercem controle sobre eles; são as formas de aparências objetivas das relações econômicas que definem o capitalismo. Se essas formas são tomadas como naturais, isso se deve à não visibilidade imediata de seu conteúdo ou essência social, que só podem ser revelados pela análise teórica.

A "reificação", da mesma forma, é um conceito marxista que define o ato (ou resultado do ato) de transformação das propriedades, relações e ações humanas em propriedades, relações e ações de coisas produzidas pelo homem, que se tornam independentes (e que são imaginadas como originalmente independentes) do homem e governam sua vida. Significa igualmente a transformação de seres humanos em seres semelhantes a coisas, que não se comportam de forma humana, mas de acordo com as leis do mundo das coisas. 
Já para Freud,${ }^{15} \mathrm{o}$ fetiche consiste em um substituto do pênis/falo inexistente na mulher, que a criança acredita ter e não quer abrir mão dessa crença. $\mathrm{O}$ fetichismo ligado à sexualidade destinase a preservar o falo na mulher e, por ser um símbolo da falta vem, ao mesmo tempo, confirmar o complexo de castração. Assim, o fetichismo freudiano denota a dificuldade dos sujeitos em lidar com limites e frustrações, defendendo-se através da relação com pessoas e coisas de forma efêmera e fugaz, marca da ideologia perversa que assim chegariam à felicidade e resolveriam todos os seus problemas.

Em "O eu e o isso", Freud ${ }^{16}$ afirma que o eu é antes de tudo corporal, estabelecendo por meio dessa instância a estreita relação entre o psiquismo e o mundo externo. Sua constituição se dá a partir do narcisismo, ${ }^{17}$ outro conceito freudiano fundamental que aponta para a relação do eu com o corpo e com o mundo dos objetos com os quais se relaciona. A construção freudiana da experiência psíquica aponta para a superação da dualidade corpo-mente, na medida em que desfaz a separação entre psiquismo e corpo. Para Freud, o eu é uma extensão da superfície corpórea, sua constituição está diretamente ligada à corporeidade. Na constituição do eu, o sujeito toma o corpo próprio como objeto de amor, consideração que permite a Freud tomar o mito de Narciso como referência para pensar essa delicada ação psíquica que permite a construção de uma instância que viabilizará o investimento libidinal no mundo objetal. É à medida que o sujeito experimenta seu corpo como primeiro objeto de amor que será possível a experiência de unidade e totalidade corporal necessárias para diferenciar-se do mundo externo.

Construída essa diferenciação mundo interno-mundo externo, é possível que o sujeito lance seus investimentos objetais no mundo, estabelecendo relações com o outro e a cultura. Nesse sentido, o ideal do eu, como instância psíquica resultante do narcisismo, tem por função medir o eu em relação aos ideais, permitindo situar-se em relação a si e ao mundo. O fetiche, por seu turno, constitui um dos objetos possíveis de investimento, seja ele o corpo, uma imagem ideal, um sapato ou até mesmo o brilho no nariz que produz o enamoramento e atende sempre aos parâmetros que se estabelecem por meio do ideal do eu.

O homem ideal veiculado na revista Men's Health ${ }^{1}$ serve muitas vezes como esse parâmetro, pois exerce a fascinação necessária para que o eu o tome como objeto de amor. O ideal do eu, articulado ao supereu, cobra, a todo momento, uma busca quimérica por cumprir suas ordens muitas vezes fantasiosa.

Christopher Lasch ${ }^{18}$ aparece como um autor que colabora com nossa argumentação, quando utiliza o narcisismo para pensar a sociedade. Criando o conceito de "Cultura do Narcisismo", argumenta que teremos um perfil cultural próximo à psicopatologia das neuroses narcísicas, psicoses e esquizofrenia. Concebe que as pessoas apresentam sintomas como falta de sentido na vida, dificuldades em se relacionar e sentimento de vazio interior. O resultado culmina em egos grandiosos, porém fracos, e extrema preocupação com interesses pessoais. ${ }^{18}$ 
O homem, não tendo mais as certezas de décadas atrás, com uma ansiedade galopante devido à velocidade do mundo contemporâneo e vivendo com medo, acaba acionando defesas psíquicas primitivas para sobreviver, configurando a cultura do narcisismo. Cotejando com os autores citados acima, percebemos a estratégia midiática em trabalhar diretamente a construção de uma "nova masculinidade", valorizando, via discursos, o narciso de todos e de cada um. A mídia amplia e reforça a insatisfação humana, colocando em seus interesses um verdadeiro ideal a ser alcançado.

Esse ideal se apresenta em um discurso que porta sentido de facilidade, rapidez e acessibilidade, vinculando-se diretamente ao corpo como o principal atributo para vencer na vida. Contudo, assim como o fetiche freudiano, esse ideal representa uma falta que, caso mantivesse sua maleabilidade, promoveria uma busca permanente em direção ao desejo. Esse aprisionamento do desejo a um ideal muitas vezes inalcançável serve na lógica marxista do fetiche.

Percebemos que a mídia investe de forma paradoxal. Por um lado, fere narcisicamente quando afirma a fragilidade humana e, por outro, inflama narcisicamente, denotando que o indivíduo só depende de si mesmo para chegar à perfeição. O individualismo é exacerbado e se torna a principal referência de mundo, tornando a sociedade um conglomerado de indivíduos autônomos e esvaziados de sua força política coletiva.

A sociedade do espetáculo ${ }^{19}$ coloca as imagens como mediadoras privilegiadas dos objetos (mercadoria) e as pessoas com suas verdades e soluções, transformando os indivíduos em reprodutores acríticos de suas ideologias sedutoras. De acordo com a lógica do fetiche marxista, esse processo contínuo se caracteriza pela ocupação de todas as dimensões da vida pela mercadoria. Tudo e todos entram em uma dinâmica de fetichização. O corpo, a masculinidade e o alimento, que são os termos privilegiados neste ensaio, são os maiores veículos subjetivadores da revista.

\section{Alimentação, ciência e gênero}

A alimentação é um componente fundamental nesse processo de construção biotecnocientífica do corpo $^{11}$ e, cada vez mais, o público masculino se vê assediado pelos meios de comunicação de massa, pelo discurso dos especialistas e fornecedores de serviços, produtos, medicamentos e alimentos que proporcionam "uma melhor performance para a máquina".

O mercado já percebeu esta lacuna, e o direcionamento das revistas voltadas para o público masculino trabalha insistentemente no sentido de produzir "um novo homem" - que se adapte à lógica do consumo descartável de bens, produtos, equipamentos e serviços voltados para a construção do corpo, a construção de uma estética "metrossexual" e o que se chama de cuidados com a saúde, que na verdade não passa de cuidado com a forma. O que é visto como saúde, na verdade, é apenas uma perspectiva ligada à medicina estética, à primazia da forma sobre o 
conteúdo, que chamaremos aqui de "estetização da saúde" - ou seja, a valorização de parâmetros estéticos como definidores das condições de saúde. ${ }^{20}$

Este processo de estetização da saúde aponta para o papel do corpo no meio social e para o processo de construção da identidade na sociedade atual, que atua na estruturação de uma nova percepção corporal. A variedade de alterações corporais (corretivas ou estéticas) às quais o corpo está sujeito hoje, a ampliação do mercado ligado ao culto ao corpo e a sua transformação e a valorização de parâmetros estéticos, como definidores das condições de saúde e da concepção do que venha a ser "saudável", nos colocam diante de diferentes questões na área da saúde que suscitam novas formas de entendimento.

Podemos observar na revista Men's Health ${ }^{1}$ uma profusão de discursos e sentidos criados que se mesclam à ideologia dominante, se confundem com os valores sociais e morais hegemônicos e colocam o corpo, ao mesmo tempo, como objeto fetiche, meio de ascensão social, organismo vital, meio de elevação, êxtase, bem-estar, prazer ou fonte da eterna juventude e uma máquina a ser alimentada. Trata-se de uma rede de discursos, saberes, sentidos, dicas, informações, valores, estratégias e soluções mágicas que atuam na superfície dos corpos, mas se recusam a habitá-los. São utilizados sem reflexão, sem crítica. Fazem com que discursos oriundos de alguns setores específicos se naturalizem, produzam sentidos e verdades, normatizem a vida, reproduzindo uma racionalidade que distancia o sujeito de seu próprio corpo. ${ }^{21}$

Segundo Ferreira, ${ }^{21}$ o corpo masculino tornou-se também um capital. Ele é uma moeda que participa da economia do mercado das trocas afetivas, sexuais, conjugais, profissionais e até existenciais. Ele é condição necessária para o alpinismo social, a felicidade e o reconhecimento social. O corpo ocupa, assim, lugar de destaque no processo de diferenciação progressiva e hierarquizada da vida social. Ele é uma forma de capital que define e é definido pelo meio social. Através dele, se produzem novos códigos e se reproduzem antigos códigos de valorização e status. Suas possibilidades estéticas permitem transitar por diferentes posições na hierarquia social, alterando e definindo trajetórias afetivas, pessoais, profissionais ou sociais, criando novos espaços na ordem social, produzindo novas formas de distinção social. O corpo trabalhado possui status próprio, como se ele não dependesse da hierarquia, embora na verdade apenas reforce as novas formas de hierarquia. ${ }^{21}$

Essa forma de produção de subjetividade não só atua individualmente, emitindo estímulos diretamente ao inconsciente, produzindo indivíduos normalizados, submetidos a um sistema hierárquico de valores e expostos à submissão, como também atua na produção de uma subjetividade social, que se manifesta na produção e no consumo, produzindo inclusive nossos sonhos, nossas paixões, nossos desejos, referências de mundo e projetos de vida. 
A construção de sentidos sobre o corpo masculino da revista Men's Health ${ }^{1}$ incorpora os sentidos trabalhados ao longo deste ensaio. O corpo é reificado, transformado em coisa, é tratado como objeto de culto e fetiche, uma mercadoria a ser exposta e consumida no mercado, é destituído de um valor singular, mas ao mesmo tempo é serializado, transformado em máquina de repetição da racionalidade instrumental que o capitalismo opera sobre os corpos, tornando-os dóceis e úteis para o sistema.

Evidencia-se a complexidade da relação entre o consumo de alimentos com a construção do corpo como um modo fundamental de pensarmos a produção subjetiva na atualidade. Para nós, o capitalismo é uma máquina de produção de sentidos que engendra papéis, desejos, pontos de vista, corporalidades e padrões estéticos variados, utilizando-se de comportamentos que tanto se prestam à submissão como à libertação. Nessa lógica, o alimento surge como produto cientificado e medicalizado que possibilita o acesso ao corpo ideal e saudável, uma vez que, ingerindo o alimento certo, o indivíduo conseguirá resolver todos seus problemas. Portanto, para que se acredite nesta ideologia, os dispositivos de poder ${ }^{22}$ exercem suas seduções estratégicas, formando insaciáveis consumidores.

Na revista, o alimento surge como o combustível necessário para a máquina produzir e consumir. Encontramos alimentos para macho, para aumentar os músculos, para melhorar um órgão do corpo ou para curar o corpo e a alma, porém nem sempre produzindo saúde. $\mathrm{O}$ alimento, nesta lógica, é reduzido a mero recipiente de nutrientes que, bem administrados, levam a máquina aos resultados esperados. Com essa racionalidade, tenta-se apagar todo o lugar social do alimento. Segundo Kraemer, Prado, Ferreira \& Carvalho: ${ }^{23}$

Os profissionais de saúde e a mídia utilizam essas recomendações para estabelecer um padrão de alimentação saudável idealizado para um indivíduo idealizado, materializado em um padrão legitimado socialmente. Enquanto a ciência e a tecnologia desenvolvem uma alimentação saudável baseada em preceitos laboratoriais e recomendações nutricionais, no imaginário simbólico construímos o desejo de um alimento capaz de fazer o ideal de saúde se tornar realidade na vida das pessoas, um alimento com poder de medicamento. Nessa perspectiva, o alimento aparece separado do contexto e das práticas cotidianas das pessoas, traduzindo em nutrientes que atendam a uma demanda fisiológica, por um lado e idealizada por outro. ${ }^{23}$

A dietética cada vez mais ganha relevância nas atuais estratégias da biopolíticas, devido à intensificação da medicalização e farmacologização da vida. ${ }^{9}$ Que os homens necessitam cuidar melhor da saúde é patente, mas como fazê-lo foi a problematização que este mosaico permite situar. Cabe ressaltar, que a intensificação com os cuidados corporais não é totalmente negativa, pois o cuidado com o corpo deixa as pessoas mais atentas aos seus processos de saúde e doença quando atendido em sua totalidade biopsicossocial. Sobretudo com os homens, que durante muito tempo 
negligenciaram e, de alguma forma, ainda negligenciam os cuidados com a saúde. No entanto, a concepção de saúde que encontramos na revista Men's Health ${ }^{1}$ não é, segundo pesquisamos, a melhor maneira de pensar a saúde dos homens, devido a subjetivação neste modelo hegemônico que limita o processo saúde-doença.

Na revista, encontramos sem esforço a subordinação das mulheres aos homens, que vem sendo trabalhada nos estudos de gênero em termos de masculinidade hegemônica. As mulheres aparecem nas capas em imagens reduzidas, nas manchetes e matérias como objeto passivo ante aos desejos masculinos, beirando a misoginia. Retiram a posição de sujeito das mulheres, devido à forma corporal e ideológica em que o homem é retratado. $\mathrm{O}$ alimento ganha extrema relevância na produção desse ser macho. Matérias que preconizam o alimento como o que promoverá a performance principalmente sexual, que colocariam as mulheres passivas e reféns deste homem.

É, portanto, exemplar como a mídia participa de forma intensa na conformação do corpo e da subjetividade do homem contemporâneo, produzindo e reproduzindo conceitos de corpo e saúde, onde o alimento tem cada vez mais protagonismo. Pela impossibilidade de alcançar os ideais veiculados como possíveis, produz uma fragmentação subjetiva que, por fazer parte da própria constituição do eu, torna-se a estratégia biopolítica de captura dos desejos para que estes atendam aos interesses do mercado e sua lógica de consumo. O "novo homem" seria, assim, uma maquiagem para reeditar a norma de gênero hegemônica. Em suma, muda-se a aparência, mas não se altera a essência do que é considerado legitimamente masculino como a virilidade, a força e a rigidez.

\section{Referências}

1. Men's Health. Rio de Janeiro: Abril; 2006-

2. Becker HS. Métodos de pesquisa em ciências sociais. 2. ed. São Paulo: Hucitec; 1994.

3. Kessler SJ, Ashenden DJ, Connell RW, Dowsett GW. Ockers and disco-maniacs. Sydney, Australia: Inner City Education Center; 1982.

4. Carrigan T, Connell RW, Lee J. Toward a new sociology of masculinity. Theory and Society 1985; 14(5):551-604.

5. Connell RW, Messerschmidt JW. Masculinidade hegemônica: repensando o conceito. Estudos Feministas 2013; 21(1):241-282.

6. Jansen SC, Sabo D. The sport-war metaphor: hegemonic masculinity, the persian-gulf war, and the new world order. Sociology of Sport Journal 1994; 11(1):1-17.

7. Ribeiro CR, Russo J. Negociando com os leitores: o "novo" e o "antigo" homem nos editoriais da revista Men’s Health. Cadernos Pagu 2014; 42:477-511.

8. Deleuze G. Conversações. Rio de Janeiro: Ed. 34; 1992. 
9. Camargo Júnior KR. A biomedicina. PHYSIS: Revista Saúde Coletiva 2005; 15(Supl.):177-201.

10. Santos BS. Um discurso sobre as ciências. São Paulo: Cortes; 2010.

11. Le Breton D. Adeus ao corpo: antropologia e sociedade. Campinas: Papirus; 2013.

12. Bauman Z. Identidade. Rio de Janeiro: Zahar; 2005.

13. Bauman Z. Vidas para consumo: a transformação de pessoas em mercadorias. Rio de Janeiro: Zahar; 2008.

14. Safatle V. Fetichismo: colonizar o outro. Rio de Janeiro: Civilização Brasileira; 2010.

15. Freud S. Fetichismo. 1927. In: Freud S. Obras completas. Buenos Aires: Amorrortu; 2006.

16. Freud S. O eu e o isso. 1923. In: Freud S. Obras completas. Buenos Aires: Amorrortu; 2006.

17. Freud S. Introdución del narcisismo. 1914. In: Freud S. Obras completas. Buenos Aires: Amorrortu; 2006.

18. Lasch C. A cultura do narcisismo. Rio de Janeiro: Imago; 1983.

19. Debord G. A sociedade do espetáculo. Rio de Janeiro: Contraponto; 2013.

20. Ferreira FR. Algumas considerações acerca da Medicina Estética. Ciênc. Saúde Coletiva 2010; 15(1):67-76.

21. Ferreira FR. Ciência, arte e cultura no corpo: a construção de sentidos sobre o corpo a partir das cirurgias plásticas. Curitiba: CRV; 2011.

22. Foucault M. Em defesa da sociedade: curso no Collège de France (1975/1976). São Paulo: Martins Fontes; 2006.

23. Kraemer FB, Prado SD, Ferreira FR, Carvalho MCVS. O discurso sobre a alimentação saudável como estratégia de biopoder. Physis 2014; 24(4):1337-1360. 
